\title{
Supraglacial debris thickness variability: impact on ablation and relation to terrain properties
}

\author{
Lindsey I. Nicholson ${ }^{1}$, Michael McCarthy ${ }^{2,3}$, Hamish D. Pritchard ${ }^{2}$, and Ian Willis ${ }^{3}$ \\ ${ }^{1}$ Department of Atmospheric and Cryospheric Sciences, Universität Innsbruck, Innsbruck, Austria \\ ${ }^{2}$ British Antarctic Survey, Natural Environment Research Council, Madingley Road, Cambridge, UK \\ ${ }^{3}$ Scott Polar Research Institute, University of Cambridge, Cambridge, UK
}

Correspondence: Lindsey I. Nicholson (lindsey.nicholson@uibk.ac.at)

Received: 23 April 2018 - Discussion started: 6 June 2018

Revised: 8 October 2018 - Accepted: 6 November 2018 - Published: 29 November 2018

\begin{abstract}
Shallow ground-penetrating radar (GPR) surveys are used to characterize the small-scale spatial variability of supraglacial debris thickness on a Himalayan glacier. Debris thickness varies widely over short spatial scales. Comparison across sites and glaciers suggests that the skewness and kurtosis of the debris thickness frequency distribution decrease with increasing mean debris thickness, and we hypothesize that this is related to the degree of gravitational reworking the debris cover has undergone and is therefore a proxy for the maturity of surface debris covers. In the cases tested here, using a single mean debris thickness value instead of accounting for the observed small-scale debris thickness variability underestimates modelled midsummer sub-debris ablation rates by $11 \%-30 \%$. While no simple relationship is found between measured debris thickness and morphometric terrain parameters, analysis of the GPR data in conjunction with high-resolution terrain models provides some insight into the processes of debris gravitational reworking. Periodic sliding failure of the debris, rather than progressive mass diffusion, appears to be the main process redistributing supraglacial debris. The incidence of sliding is controlled by slope, aspect, upstream catchment area and debris thickness via their impacts on predisposition to slope failure and meltwater availability at the debris-ice interface. Slope stability modelling suggests that the percentage of the debris-covered glacier surface area subject to debris instability can be considerable at glacier scale, indicating that up to $32 \%$ of the debris-covered area is susceptible to developing ablation hotspots associated with patches of thinner debris.
\end{abstract}

\section{Introduction}

Debris-covered glaciers are the dominant form of glaciation in the Himalaya (e.g. Kraaijenbrink et al., 2017) and are common in other tectonically active mountain ranges worldwide (Benn et al., 2003). Supraglacial debris cover alters the rate at which underlying ice melts in comparison to clean ice in a manner primarily governed by the thickness of the debris cover (e.g. Østrem, 1959; Loomis, 1970; Mattson et al., 1992; Kayastha et al., 2000; Nicholson and Benn, 2006; Reid and Brock, 2010): A thin supraglacial debris cover ( $<$ a few $\mathrm{cm}$ ) enhances melt, while thicker debris cover reduces melt by insulating the ice beneath from surface energy receipts. Prevailing weather conditions and local debris properties, such as albedo, lithology, texture and moisture content, also influence the amount of energy available for sub-debris ablation and modify the exact relationship between debris thickness and ablation rate, but the general characteristics of the so-called $\emptyset$ strem curve are robust, further demonstrating the dominant role of debris thickness in this relationship (Fig. 1).

Both theory and observations indicate that the spatial variability of supraglacial debris thickness typically has both a systematic and a non-systematic component. Debris thickness tends to increase towards the glacier margins and terminus due to concentration by decelerating ice velocity and increasing background melt-out rate (e.g. Kirkbride, 2000). This systematic variation is evident in field measurements of debris cover thickness (e.g. Zhang et al., 2011) and in characterizations of debris thickness as a function of the surface temperature distribution observed from satellite imagery (e.g. Mihalcea et al., 2006, 2008a, b; Foster et al., 2012; Rounce and McKinney, 2014; Schauwecker et al., 2015; Gib- 


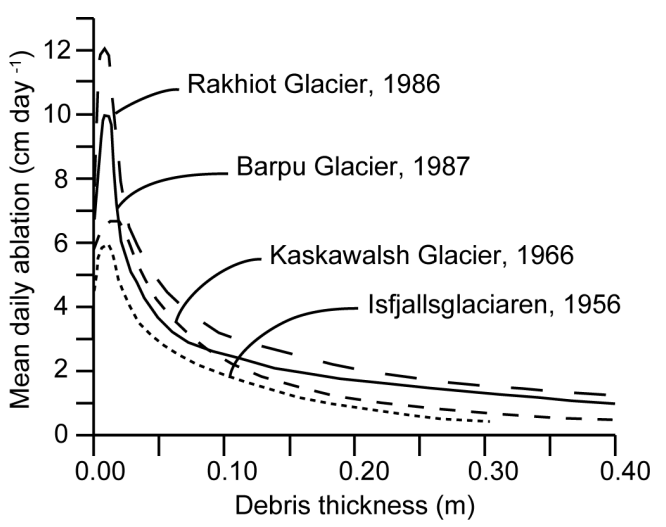

Figure 1. Examples of the relationships between supraglacial debris thickness and underlying ice ablation rate at different glacier sites, redrawn from Mattson et al. (1993). The exact form of this relationship at each site varies with prevailing meteorological conditions and debris properties, but its general character is preserved.

son et al., 2017). At local scales, debris thickness varies less systematically according to the input distribution, local melt-out patterns and gravitational and meltwater reworking of the supraglacial debris. Manual excavations (e.g. Reid et al., 2012), observations of debris thickness made above exposed ice cliffs (e.g. Nicholson and Benn, 2012; Nicholson and Mertes, 2017) and debris thickness surveyed by groundpenetrating radar (McCarthy et al., 2017) demonstrate that debris thickness varies considerably over short horizontal distances. Thus, the thickness of debris over a sampled area of glacier surface is better expressed as a probability density function than a single value (e.g. Nicholson and Benn, 2012; Reid et al., 2012).

Exposed ice faces within debris-covered glacier ablation areas are known to contribute disproportionately to glacier ablation compared to their area (e.g. Sakai et al., 2000; Juen et al., 2014; Buri et al., 2016; Thompson et al., 2016), and it has been proposed that such "ablation hotspots", along with stagnation, are the reasons for the observed similarity in surface lowering rates of otherwise comparable clean and debris-covered ice surfaces (e.g. Kääb et al., 2012; Nuimura et al., 2012). Given the strongly non-linear relationship between ablation rate and debris thickness (Fig. 1), patches of thinner debris within a generally thicker supraglacial debris cover can similarly be expected to contribute disproportionately to glacier ablation, but this has only rarely been considered (Reid et al., 2012). The implication of this would be that calculations of sub-debris ice ablation rate and meltwater production using spatially averaged mean debris thickness may differ substantially from the actual meltwater generated from a debris layer of highly variable thickness within the same area. Therefore, there remains a critical need to be able to quantify not only mean supraglacial debris thickness, but also local debris thickness variability in order to understand how debris cover is likely to impact glacier behaviour, melt- water production and contribution to local hydrological resources and global sea level rise.

Meeting this need requires a better understanding of debris thickness variability and the controls upon it, ideally by means of more readily observable properties. Topographic data have been used to predict soil thickness on hilly, extraglacial terrain under the assumption of steady-state conditions (e.g. Pelletier and Rasmussen, 2009). However, associated soil thickness relationships as a function of slope curvature (Heimsath et al., 2017) are based on progressive creep processes, while reworking of supraglacial debris cover occurs mainly as a result of gravitational instabilities such as "topples, slides and flows" (Moore, 2017). Nevertheless, as the debris thickness that can be supported on a slope is related to slope angle, debris texture and saturation conditions (Moore, 2017), it might still be possible to find explicit relationships between topography and debris thickness. If highresolution topography data, which are increasingly widely available, could be used to indicate local debris thickness variability, this information would complement spatially averaged mean supraglacial debris thickness values derived by other methods (cf. Arthern et al., 2006).

\section{Aim of the study}

This study investigates the evidence for small-scale debris thickness variability, assesses the impact of local debris thickness variability on calculated sub-debris ice ablation rates and explores the potential for predicting local debris thickness variability from morphometric terrain parameters. First, debris thickness data from shallow ground-penetrating radar surveys are used to characterize the small-scale spatial variability of debris thickness on a Himalayan glacier, examine evidence of gravitational reworking processes and compare the observed variability to previously published data. Second, the impact of the observed small-scale debris thickness variability on modelled sub-debris ablation rates is assessed. Third, a contemporaneous high-resolution terrain model and optical imagery are employed to determine whether the observed thickness variability can be predicted from more readily measured surface terrain properties. Finally, a slope stability model is calibrated with the GPR and ablation model data and used to determine the percentage of our study areas in the debris-covered ablation zone that are subject to debris instability and potentially the formation of ablation hotspots in mid-ablation season (August) conditions.

\section{Study site and data}

The Ngozumpa Glacier is a large dendritic debris-covered glacier of the eastern Himalaya, located in the upper Dudh Kosi catchment, Khumbu Himal, Nepal (Fig. 2a). The glacier has a total area of $61 \mathrm{~km}^{2}$, of which the lower $22 \mathrm{~km}^{2}$ is heav- 

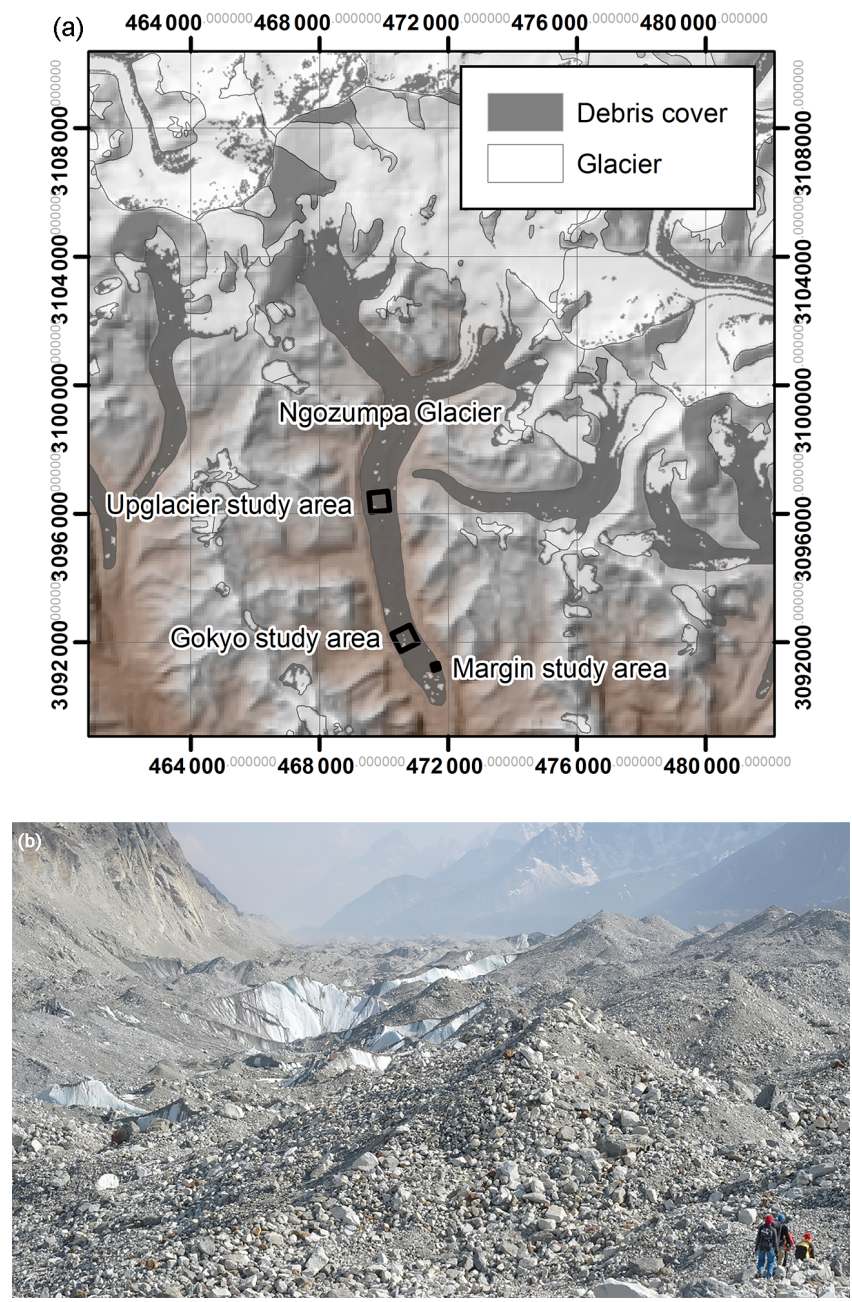

Figure 2. (a) Ngozumpa Glacier showing the key study areas, $\sim 7,2$ and $1 \mathrm{~km}$ from the glacier terminus. (b) Photograph showing example of hummocky terrain in the upglacier study area note the people for scale in the bottom-right corner. Photo credit: Hamish Pritchard.

ily debris covered, with hummocky surface relief of the order of $50 \mathrm{~m}$ over distances of $100 \mathrm{~m}$ (Fig. 2b), studded with supraglacial ponds and exposed ice cliffs (Benn et al., 2001). The NE and E branches are no longer connected dynamically to the main trunk (Thompson et al., 2016), which is fed solely by the $\mathrm{W}$ branch descending from the flanks of Cho Oyu $(8188 \mathrm{~m})$. The southernmost $6.5 \mathrm{~km}$ of the glacier is nearly stagnant (Quincey et al., 2009) and has a low surface slope of $\sim 4^{\circ}$. The terrain of this glacier, its wasting processes and the evolution of surface lakes have been well studied through a series of previous publications (Benn et al., 2000, 2001; Thompson et al., 2012, 2016), as have the debris properties including limited measurements of debris thickness (Nicholson and Benn, 2012).

Debris thickness over much of the debris-covered area is in excess of $1.0 \mathrm{~m}$ precluding widespread manual excavation.
However, in 2001 measurements of debris thicknesses exposed above ice cliffs were made by theodolite survey at $\sim 1$ and $7 \mathrm{~km}$ from the terminus (Nicholson and Benn, 2012). These data provided only coarse estimates of debris thickness as neither the slope angle of the debris exposure nor the impact of the theodolite bearing angle were accounted for in the vertical offsetting used to obtain the debris thickness. In April 2016 terrestrial photogrammetry was used to create a high-resolution scaled model of the local glacier surface from which debris thickness estimates were made in a manner analogous to the theodolite survey at a location $\sim 2 \mathrm{~km}$ from the terminus near Gokyo village (Nicholson and Mertes, 2017). At the same time, several GPR surveys, totalling $3301 \mathrm{~m}$, were undertaken in this area and a single $238 \mathrm{~m}$ GPR survey was done close to the glacier margin $\sim 1 \mathrm{~km}$ from the glacier terminus (Fig. 2a). Meteorological data are not available from the Ngozumpa Glacier surface at this site, so the ablation model was forced using meteorological data measured at the Pyramid weather station $\left(27.95^{\circ} \mathrm{N}, 86.81^{\circ} \mathrm{E} ; 5035 \mathrm{~m}\right.$ a.s.1.) operated by the Ev-K2CNR consortium (http://www.evk2cnr.org/cms/en, last access: 22 November 2018) in the neighbouring valley. A digital terrain model generated from Pleiades tri-stereo imagery acquired in April 2016 (Rieg et al., 2018) is used to relate the measured debris thicknesses to the glacier surface terrain.

\section{Methods}

\subsection{GPR debris thickness data collection and processing}

GPR measurements were made between 31 March and 20 April 2016 broadly following the methods of McCarthy et al. (2017). Debris thickness was sampled in 36 individual radar transects, covering sloping and level terrain with coarse and fine surface material. The GPR system was a dualfrequency $200 / 600 \mathrm{MHz}$ IDS RIS One, mounted on a small plastic sled and drawn along the surface. Data were collected to a Lenovo Thinkpad using the IDS K2 FastWave software. This system produces two simultaneous radargrams for each acquisition. The 200 and $600 \mathrm{MHz}$ antennas have separation distances of 0.230 and $0.096 \mathrm{~m}$ respectively. Data acquisition used a continuous step size, a time window of $100 \mathrm{~ms}$ and a digitization interval of $0.024 \mathrm{~ns}$. The location of the GPR system was recorded simultaneously at $1 \mathrm{~s}$ intervals by a lowprecision GPS integrated with the IDS, which assigns a GPS location and time directly to every twelfth GPR trace and by a more accurate differential GPS (dGPS) system consisting of a Trimble XH and Tornado antenna mounted on the GPR and a local base station of a Trimble Geo7X and Zephyr antenna.

Radargrams were processed in REFLEXW (Sandmeier software) by applying the steps shown in Table 1 . The reflection at the ice surface was picked manually wherever 
Table 1. Details of processing steps applied to radargrams in order of use from left to right, using REFLEXW software. $T$ is the period of the transmitted signal, $t$ is two-way travel time and $f$ is operating frequency.

\begin{tabular}{lllllllll}
\hline $\begin{array}{l}\text { Operating } \\
\text { frequency } \\
\text { (MHz) }\end{array}$ & $\begin{array}{l}\text { Plateau } \\
\text { declip }\end{array}$ & $\begin{array}{l}\text { DC } \\
\text { shift }\end{array}$ & Dewow (ns) & $\begin{array}{l}\text { Align } \\
\text { first } \\
\text { breaks }\end{array}$ & $\begin{array}{l}\text { TimeZero } \\
\text { correct (s) }\end{array}$ & $\begin{array}{l}\text { Back- } \\
\text { ground } \\
\text { removal }\end{array}$ & $\begin{array}{l}\text { Bandpass } \\
\text { filter }\end{array}$ & Gain \\
\hline 200 & whole & whole & $1.5 T(7.5)$ & whole & $7.6719 \mathrm{e}^{-10}$ & whole & $0.25 f, 0.5 f$, & divergence compensation \\
600 & profile & profile & $1.5 T(7.5)$ & profile & $3.2022 \mathrm{e}^{-10}$ & profile & $1.5 f, 3 f$ & (scaling $0.1 t)$ \\
\hline
\end{tabular}
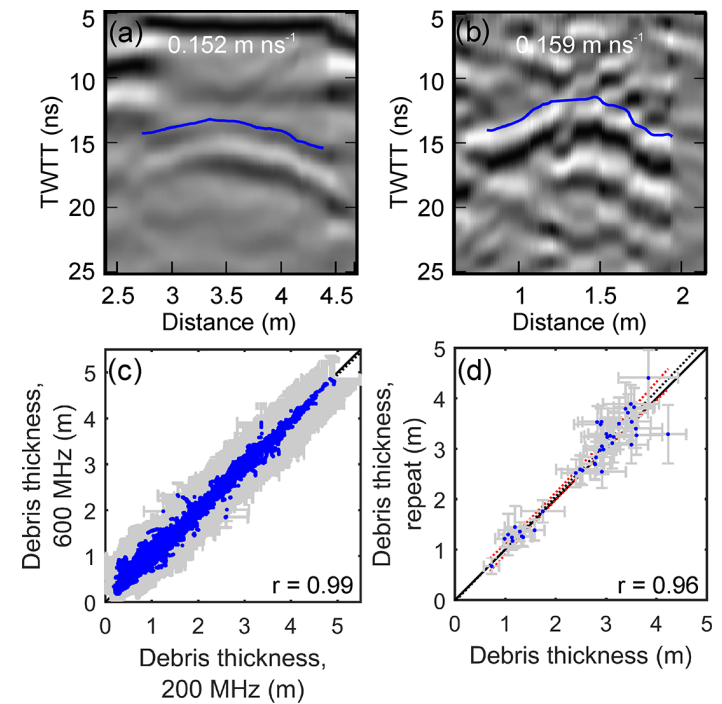

Figure 3. Reflector used to identify signal velocity on Ngozumpa Glacier in (a) fine-grained sediments and (b) coarse-grained sediments. Comparison of picked debris-ice interface depths sampled simultaneously with different frequencies (c) and at transect intersection points (d).

it was clearly identifiable and was not picked if it was indistinct. The appropriate signal velocity for the supraglacial debris was obtained by burying a $1.5 \mathrm{~m}$ long steel bar to a known depth and then passing the GPR over the buried target and picking the two-way travel time to its reflection (Fig. 3a and b). Both fine and coarse material gave similar wave speeds $\left(0.15\right.$ and $\left.0.16 \mathrm{mns}^{-1}\right)$. These were averaged to obtain a bulk value that is considered representative of all the radar lines measured and is comparable to values from the debris-covered Lirung Glacier, central Nepal (McCarthy et al., 2017). Debris thickness was calculated using two-way travel times from the ice surface and the mean of the two wave speed measurements $\left(0.16 \mathrm{~m} \mathrm{~ns}^{-1}\right)$, taking the geometry of the GPR system into account. Uncertainties were propagated according to McCarthy et al. (2017) and range from 0.14 to $0.83 \mathrm{~m}$, generally increasing with debris thickness.

During processing, the integrated GPS locations (typical accuracy of $\sim 3 \mathrm{~m}$ ) were substituted for dGPS locations (typical post-processed accuracy of $<0.05 \mathrm{~m}$ ) by matching GPS and dGPS timestamps. Where differential correction was not possible due to a lack of visible satellites, the integrated GPS locations were used. The locations of GPR data collected between timestamps were interpolated linearly in REFLEXW. Where the ice surface was identifiable in radargrams of both frequencies, the measurement made using the higher frequency was assigned because higher frequencies give higher precision. GPR data quality was assessed by comparing debris thicknesses calculated using picks from the two different frequencies in the same location (Fig. 3c) and by comparing debris thicknesses at transect crossover points (Fig. 3d). In both cases, points fit well to the $1: 1$ line. To show how debris thickness varies with topography, radargrams were topographically corrected for display purposes after the ice interface had been picked.

\subsection{Ablation modelling}

In the absence of suitable field measurements of sub-debris ice ablation, a model of ice ablation beneath a debris cover was applied to assess the impact of debris thickness variability on calculated ablation rates. As recent, high-quality, local meteorological data are not available to force a timeevolving numerical model, typical ablation season conditions measured at the nearby Pyramid weather station were used to force a steady-state model of sub-debris ice ablation that has been previously published and evaluated against field data (Evatt et al., 2015).

Ice ablation conditions are generally restricted to the summer months in the eastern Nepalese Himalaya (Wagnon et al., 2013). For the illustrative simulations performed here, the model was forced with mean August meteorological conditions from 2003 to 2009 (<2\% of August hourly data are missing) and assuming the ice temperature to be $0^{\circ} \mathrm{C}$. This provides forcing variables of air temperature $\left(3.27^{\circ} \mathrm{C}\right)$, incoming shortwave $\left(208 \mathrm{Wm}^{-2}\right)$ and longwave $\left(314 \mathrm{Wm}^{-2}\right)$ radiation, wind speed $\left(1.94 \mathrm{~ms}^{-1}\right)$ and relative humidity (97\%). Appropriate debris properties for dry debris in summer time on the Ngozumpa Glacier were adopted from Nicholson and Benn (2012), whereby debris properties of effective thermal conductivity, dry surface albedo and porosity were taken to be $1.29 \mathrm{Wm}^{-1} \mathrm{~K}^{-1}, 0.2$ and 0.3 respectively. Ice albedo, debris thermal emissivity and the debris surface roughness length, friction velocity and exponential decay rate of wind were adopted from Evatt et al. (2015). 
The model is used to generate an Østrem curve and associated surface debris temperature for the stated inputs, as a function of debris thickness. The model does not account for variability in surface energy receipts due to local or surrounding terrain, or the effects of spatially or temporally variable debris properties other than thickness, and the chosen input properties are only approximate. However, this does not preclude its illustrative use in investigating the influence of variable debris thickness on calculated ablation rate. Modelling was carried out for three sites for which local debris thickness data are available: (i) the margin study area $\sim 1 \mathrm{~km}$ from the glacier terminus, (ii) the main Gokyo study area $\sim 2 \mathrm{~km}$ from the terminus, both measured by GPR in 2016, and (iii) the upglacier study area $\sim 7 \mathrm{~km}$ from the terminus, measured by theodolite survey in 2001 (Fig. 2). Ablation rate and surface temperature calculated for the mean debris thickness is compared to that yielded by multiplying the percentage frequency distribution of debris thickness with the modelled Østrem and surface temperature curves. Ablation totals for the month of August are calculated and that derived using the mean debris thickness value is expressed as a percentage deviation of that derived using locally variable debris thickness. Used in this form, we assume the model itself to be error-free. To isolate the error associated with debris thickness, all other model inputs are also assumed to be error-free. Each GPR debris thickness has an associated error, but as no quantified error assessment is available for the thickness values measured by theodolite at $7 \mathrm{~km}$ from the terminus, a fixed error of $\pm 0.15 \mathrm{~m}$ was applied to these data. The model was run with maximum and minimum debris thickness values according to the assigned errors to provide an indication of uncertainty of the reported percentage difference in monthly total ablation.

\subsection{Terrain analysis}

In order to assess the static relationship between the debris distribution and terrain properties, we used a $5 \mathrm{~m}$ resolution digital terrain model (DTM) derived from Pléiades optical tri-stereo imagery taken during the field campaign on 12 April 2016. The DTM was generated from photogrammetric point clouds extracted from the Pléiades imagery, using a semi-global matching (SGM) algorithm (Hirschmüller, 2008) within the IMAGINE photogrammetry suite of ERDAS IMAGINE. The three images of each triplet were imported and the rational polynomial coefficients (RPCs) provided with the Pléiades data were used to define the initial functions for transforming the sensor geometry to image geometry. With those transformation functions, individual geometries of each image in the triplet were orientated relative to each other. To obtain the most accurate exterior orientation possible, initial RPC functions were refined using automatically extracted tie points. The calculated point clouds were then filtered for outliers, mainly found in very steep and shaded areas, using local topographic 3-D filters applied in SAGA GIS software, and converted into a $5 \mathrm{~m}$ resolu- tion DTM using the average elevation of all points within one raster cell as the elevation value for the cell. Gaps were present in very steep areas, where there was cloud, and in areas with low contrast because of fresh snow or liquid water.

Terrain properties were extracted using the ArcGIS tools Slope, Aspect and Curvature. GPR data were resampled to the same resolution as these rasters $(5 \mathrm{~m})$ by taking the mean of the measurements that occurred within each pixel. This was done using the Point to Raster tool in ArcGIS. GPR data within $5 \mathrm{~m}$ of ice cliffs were excluded for comparisons made between debris thickness and topography in order that their slope, aspect and curvature were not misrepresented. Similarly, GPR data for which dGPS locations were not available were excluded due to their lack of positional accuracy.

Ponded water at the surface is associated with the deposition of layers of fine sediments and rapid sedimentation by marginal slumping (Mertes et al., 2017). The recent history of ponded water on the parts of the glacier surface sampled by the radar transects was mapped using air photographs from 1984 and seven cloud-free optical satellite images spanning 2008-2016. These images consisted of six DigitalGlobe images, one CNES/Astrium image, all obtained via Google Earth, and the optical image from the 2016 Pleiades acquisition used to generate the DTM.

\subsection{Slope stability modelling and classification}

Slope stability modelling was carried out following Moore (2017). For the three study areas shown in Fig. 2, debris was classified as either stable or unstable. Unstable debris was further classified as being unstable due to the following:

1. oversteepening, where surface slope exceeds the debrisice interface friction coefficient;

2. saturation excess, where the modelled water table height is greater than the debris thickness; and

3. meltwater weakening, where the modelled water table height is less than the debris thickness, but debris pore pressures are sufficiently raised to cause instability.

Surface slope (see Sect. 4.3), modelled midsummer ablation rate (see Sect. 4.2), upstream contributing area and mean debris thickness (see Sect. 4.1) were used as inputs to the model. Upstream contributing area was determined from the DTM in ArcGIS using the Flow Direction and Flow Accumulation tools. Sinks in the DTM were filled if they were less than $3 \mathrm{~m}$ deep, following Miles et al. (2017), using the ArcGIS Sink and Fill tools. Surface water flow paths were also determined using the Stream To Feature tool.

The model also requires input values for the debris-ice interface friction coefficient, the densities of water and wet debris, and the saturated hydraulic conductivity of the debris. A value of 0.5 was used for the debris-ice interface 
friction coefficient, following Barrette and Timco (2008) and Moore (2017). Values of 1000 and $2190 \mathrm{~kg} \mathrm{~m}^{-3}$ were used for the densities of water and wet debris, respectively, where wet debris was assumed to have a porosity of 0.3 , after Conway and Rasmussen (2000), and the density of rock was assumed to be $2700 \mathrm{~kg} \mathrm{~m}^{-3}$ after Nicholson and Benn (2006). The saturated hydraulic conductivity of the debris, which is the parameter around which there is most uncertainty, was determined using the GPR data. Sections of the GPR transects, and subsequently their corresponding DTM pixels were defined by visual inspection on the basis of the debris morphology as either stable or unstable. Sections of thin debris on steep slopes were considered to be unstable if they occurred among sections of thick debris on shallow slopes. Sections of anything not considered to be unstable were considered to be stable. Debris stability was then modelled for the same DTM pixels using a wide range of conductivity values. The conductivity value that minimized the difference between the number of pixels that were modelled and observed as being stable or unstable was considered to be optimal. Minimization was carried out using ROC analysis, following Fawcett (2006) and Herreid and Pellicciotti (2018). The resulting saturated hydraulic conductivity value of $40 \mathrm{~m} \mathrm{~d}^{-1}$ is well within the expected range of $10^{-7}-10^{3} \mathrm{~m} \mathrm{~d}^{-1}$ (Fetter, 1994) and is consistent with the debris being well drained.

The percentage areal coverage of debris instability was calculated for each of the three study areas (Fig. 2). This was done both including and excluding ice cliffs and ponds, where ice cliffs and ponds were manually digitized from the orthophoto associated with the DTM.

The GPR data, DTM and associated orthophoto were collected in March-April 2016, while slope stability modelling was carried out using midsummer (August) ablation rates. It is likely that the debris on a given slope becomes more or less stable seasonally with changes in ablation rates. However, GPR observations of debris instability in March-April are likely to be representative of midsummer debris instability for saturated hydraulic conductivity as maximum melt is expected in midsummer. Similarly, while pond incidence and area vary seasonally on Himalayan glaciers, seasonal ponds commonly reform at the same sites (Miles et al., 2016), so manually digitized ponds and ice cliffs for March-April are assumed to be broadly representative of ponds and ice cliffs in midsummer for percentage area debris instability calculations excluding ponds and ice cliffs. Finally, model results should be treated only as a best approximation because the model assumes debris thickness and ablation rate are spatially homogeneous in each study area, which, as discussed by Moore (2017), is clearly not the case.

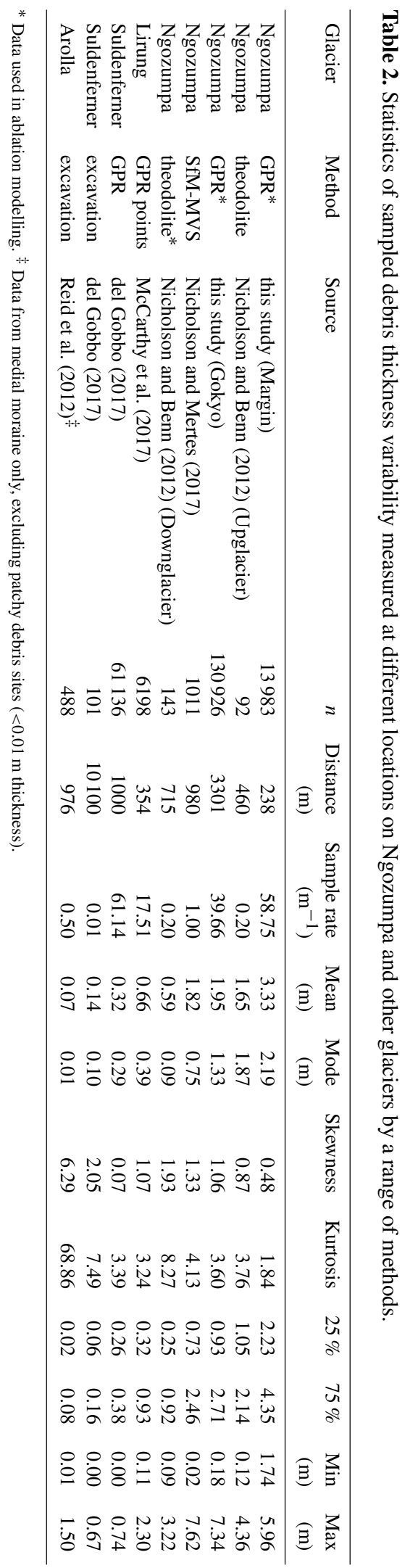

www.the-cryosphere.net/12/3719/2018/ 

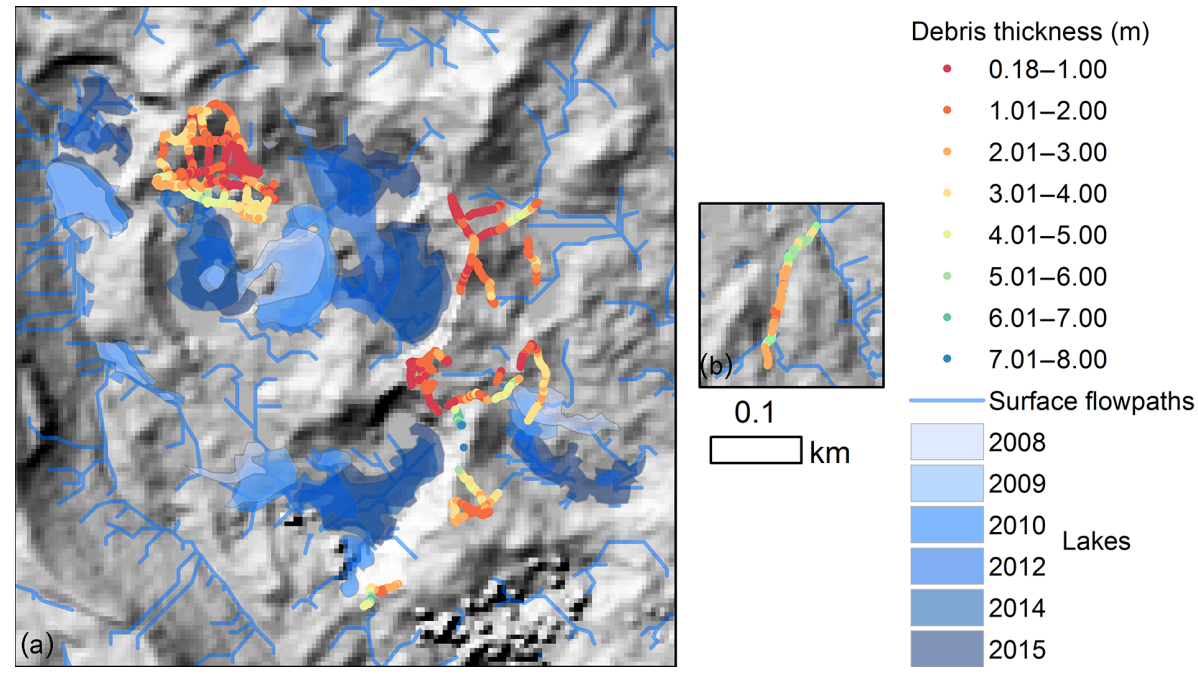

Figure 4. Overview map of GPR debris thickness sampled on Ngozumpa Glacier in 2016 overlaid on the hillshade from the Pleiades DTM, recent surface pond evolution and surface flow paths for the Gokyo (a) and Margin (b) study areas (Fig. 2).

\section{Results and discussion}

\subsection{GPR debris thickness and variability}

The quality of the GPR data is generally high. The ice surface was clearly identifiable through the debris in the majority of the radargrams collected. This is likely because the GPR system was used in continuous mode and appropriate acquisition parameters were used. For those radargrams in which the ice surface was not easily identifiable, the debris was generally too thick. This means there is the possibility of a slight thin bias in the data. However, penetration depth was often greater than $7 \mathrm{~m}$, which is likely near the maximum debris thickness. Debris thickness was found to be highly variable with a total range of 0.18 to $7.34 \mathrm{~m}$ (Fig. 4 and examples in Fig. 5). There is coherent structure to the debris thickness variation along transects (Fig. 4): In some areas, changes in debris thickness along the transect are gradual, while in a number of cases, there are abrupt changes in debris thickness along a transect associated with pinning points or topographic hollows and cavities in the underlying ice, which the debris cover fills (see Sect. 5.3 and Fig. 6).

Simple statistics of the debris thickness derived from the GPR samples of this study compared with debris thickness data sets available from other glaciers are given in Table 2. Mean debris thickness measured by GPR towards the glacier margin is thicker, and shows wider spread and lower skewness and kurtosis, than the GPR thickness data collected at the Gokyo study area (Table 2; Figs. 4, 5a-c). The percentage frequency histogram of GPR debris thickness from the glacier margin has a similar shape, but a positive offset compared to data obtained by surveying ice faces about $1 \mathrm{~km}$ from the glacier terminus in 2001, while the GPR data from Gokyo agree closely with the estimates of debris thick- ness from the photographic terrain model (Nicholson and Mertes, 2017). The 2001 surveyed debris thickness data from further upglacier (Nicholson and Benn, 2012) are thinner, more skewed and have higher kurtosis than the sites further downglacier (Fig. 5a-c).

Clearly, while debris thickness shows small-scale variability in all cases on the Ngozumpa Glacier, the details of that variability differ from site to site. This is also observed when considering data from other glaciers (Table 2; Fig. 5). Debris thickness at the Lirung Glacier in central Nepal shows a bimodal distribution not replicated at the other sites. This is suspected to be due at least partly to sampling bias, as the measurements were made to test the GPR method rather than to characterize typical debris thickness at this glacier. At Suldenferner, in the Italian Alps, debris thickness measured across the whole debris-covered area by excavation and along cross- and downglacier transects by GPR shows a substantially thinner mean than the Himalayan cases, with greater skewness and kurtosis. The debris cover on the medial moraine of Haut Glacier d'Arolla in the Swiss Alps is even thinner with yet more pronounced skewness and kurtosis. Thus, debris thickness variability at the Alpine sites shown here is more comparable to that of the upper Ngozumpa, while the Lirung Glacier measurements appear broadly more similar to sites further downglacier on the Ngozumpa Glacier.

The medial moraine on Haut Glacier d'Arolla emerged during glacial recession in the second half of the 20th century (Reid et al., 2012), offering an example of a recently developed debris cover. The debris-covered part of Suldenferner developed its continuous debris cover since the beginning of the 19th century, when the glacier was mapped with debris cover below $\sim 2500 \mathrm{~m}$ and only surficial medial moraine bands extending up to $2700 \mathrm{~m}$ (Finsterwalder and 

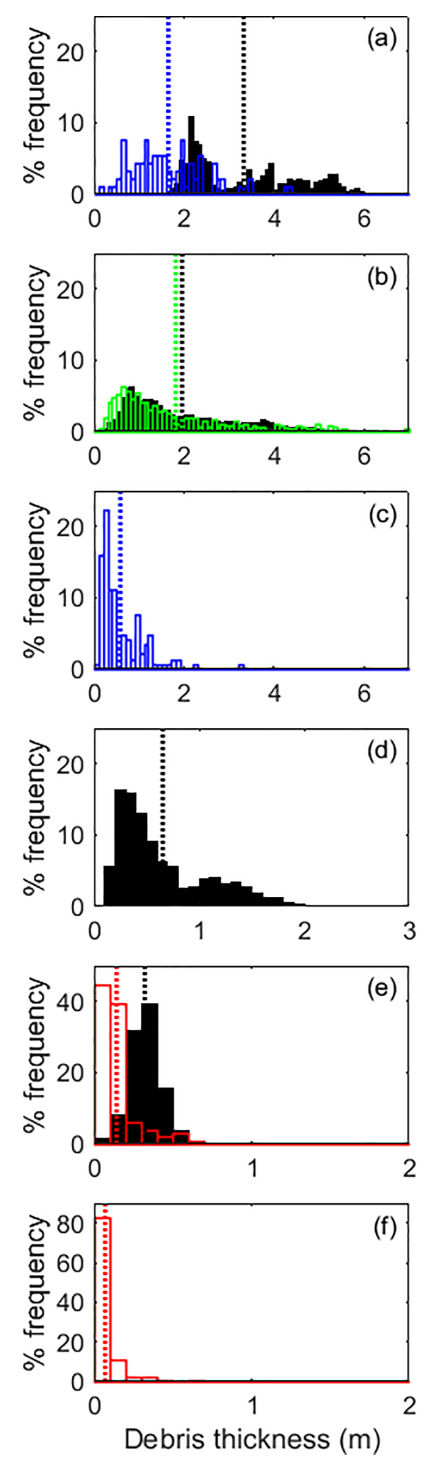

Figure 5. Percentage frequency histograms of debris thickness $\left(h_{\mathrm{d}}\right)$ in $0.05 \mathrm{~m}$ intervals at (a) the lower Ngozumpa about $1 \mathrm{~km}$ from the terminus; (b) the Gokyo area of Ngozumpa, about $2 \mathrm{~km}$ from the terminus; (c) the upper Ngozumpa, about $7 \mathrm{~km}$ from the terminus; (d) over the lower tongue of Lirung Glacier in central Nepal; (e) across the debris-covered ablation area of SuldenfernerGhiacciaio de Solda in the Italian Alps; (f) the medial moraine of Haut Glacier d'Arolla in the Swiss Alps. Measurement methods are GPR (black), theodolite surveys (blue), structure from motion (SfM-MVS) photographic terrain model (green) and excavation of pits (red). Note that axes vary between sites, and summary statistics of these distributions are in Table 2.

Lagally, 1913). The Nepalese glaciers are thought to have been debris covered for longer (Rowan, 2016), although it remains unclear when their debris covers first developed.

The percentage frequency distributions shown in Fig. 5, viewed in the context of the relative "maturity" of the debris covers sampled, are suggestive of a progressive change in skewness and kurtosis of debris thickness variability over time, as debris accumulates and undergoes progressively more gravitational reworking. The more mature debris covers on the Ngozumpa and Lirung glaciers are generally thick and characterized by hummocky terrain (cf. Fig. 2b), dissected with ponds and ice faces, whereas the less mature debris cover on Suldenferner is generally thinner and the terrain is less hummocky, with relief primarily associated with incision by supraglacial streams. Similarly, the observed progressive change in thickness and skewness/kurtosis of the debris sites downglacier on the Ngozumpa Glacier would reflect the downglacier increase in maturity of the debriscovered surface.

\subsection{Ablation modelling using mean and variable debris thickness}

Ablation was calculated for three locations on the Ngozumpa Glacier (Fig. 2) encompassing different mean debris thickness and debris thickness variability (Figs. 5, 6a), which might reflect different stages in debris cover maturity (see Sect. 5.1), but it should be noted that the sampling method and sample number differ between locations (Table 2).

The ablation calculated for typical August conditions using the mean debris thickness for each location on the glacier totalled $0.07,0.11$ and $0.32 \mathrm{~m}$ of ice surface lowering over the month at the 1,2 and $7 \mathrm{~km}$ sites respectively. This agrees with the general expected patterns of ablation gradient reversal towards the terminus of a debris-covered glacier (e.g. Benn and Lehmkuhl, 2000; Bolch et al., 2008; Benn et al., 2017). Accounting for the percentage frequency distribution of debris thickness increased the monthly total surface lowering due to ablation to $0.08,0.16$ and $0.46 \mathrm{~m}$, at 1,3 and $7 \mathrm{~km}$ respectively. In these illustrative examples, using a mean debris thickness instead of the local frequency distribution of debris thickness underestimates the ablation rate at these sites by $11 \%-30 \%$ over typical August conditions (Fig. 6c). These values are specific to the cases presented here but can be considered indicative of the order of the effect of using mean debris thickness instead of the local variable debris thickness. Considering the maximum and minimum error bounds of the debris thickness distribution (Fig. 6a and c) increases the range of this underestimate to $10 \%-40 \%$. This suggests that local mean debris thickness, and also other measures of central tendency (tested but not shown), are likely to be poor metrics for ablation modelling for typical debris cover. Instead, sufficient data points of debris thickness used to capture the local variability are likely to give a more reliable ablation estimate from model simulations. As the melt rate in the thin debris part of the Østrem curve responds more sensitively to changes in debris thickness than it does in the thick debris part of the curve, the impact of accounting for local spatial variability in debris thickness varies inversely with debris thickness (Fig. 6c). This is compounded by the fact that thinner debris appears to have more skewness and kur- 

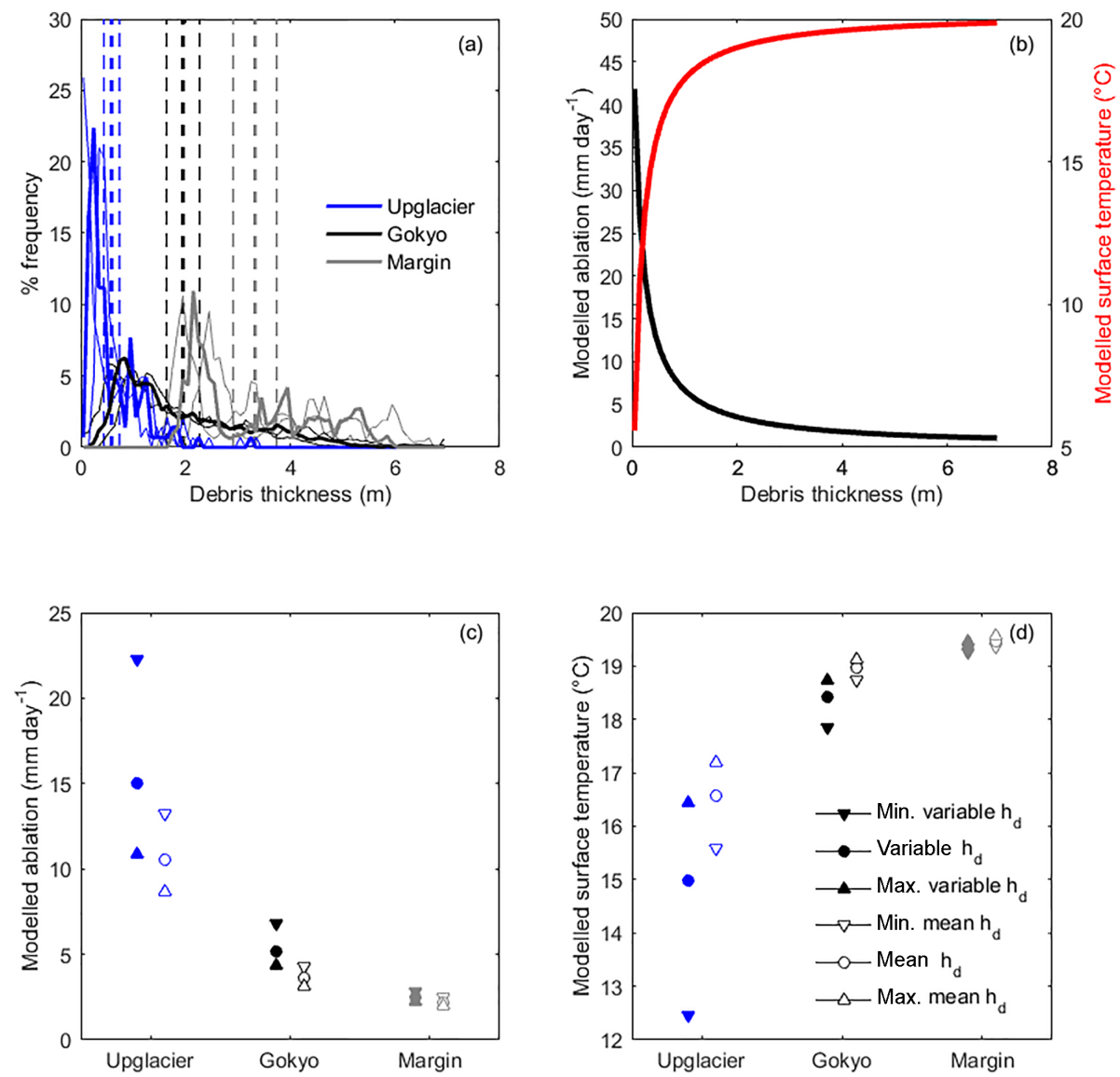

Figure 6. (a) Percentage frequency distributions from three locations on Ngozumpa Glacier, showing the mean debris thickness at each site in dotted vertical lines: $3.33,1.95$ and $0.59 \mathrm{~m}$ thick respectively at 1,2 and $7 \mathrm{~km}$ from the terminus. Thinner lines show the values for the maximum and minimum debris thickness conditions calculated from the limits of the individual debris thickness errors. (b) Modelled Østrem curve and surface temperature for mean August conditions. (c) Comparison of modelled ablation for different representations of the debris thickness at each site. (d) Comparison of modelled surface temperature for different representations of the debris thickness at each site.

tosis in the percentage frequency distribution of debris thickness, meaning that the offset between the calculated mean debris thickness and the typical debris thickness is likely to be greater.

Highly variable debris thicknesses can be expected to impact methods of mapping debris thickness using thermalband satellite imagery, as our data show that the debris thickness variability within individual pixels of a thermal band satellite image may be large. The modelled surface temperatures for mean August conditions were 19.5, 19.0 and $16.6^{\circ} \mathrm{C}$ for the mean debris thickness at the margin, Gokyo and upglacier study areas respectively. Accounting for the local debris variability at the lowest site altered the calculated surface temperature by $<0.1{ }^{\circ} \mathrm{C}$, and, at the middle and upper locations, reduced the calculated surface temperatures by 0.5 and $1.5^{\circ} \mathrm{C}$ respectively (Fig. $6 \mathrm{~d}$ ). This highlights the manner in which variable debris thickness can be expected to influence the pixel values in satellite thermal imagery, whereby a mean debris thickness calculated from a pixel temperature can be expected to underestimate the true mean debris thickness.

\subsection{Relationships between debris thickness and terrain properties}

Visual inspection of the radargrams indicates that the thinnest debris cover occurs on steep slopes (Fig. 7a and b). On the basis that slope failure typically redistributes mass from areas of high slope angle and that debris sliding was often experienced while collecting the GPR data, it seems likely that this is the result of high debris export rates in these areas due to frequent or recent slope failure in the form of sliding events (cf. Lawson, 1979; Heimsath et al., 2012). Here, the debris surface is approximately parallel to the ice surface, and this appears to be a characteristic of debris covers at or near the limits of gravitational instability. Localized areas of thick debris are found below steep slope sections in the form of infilled ice-surface depressions. Modelled surface flow paths (Fig. 7b) cross-cut the GPR transects where these depres- 

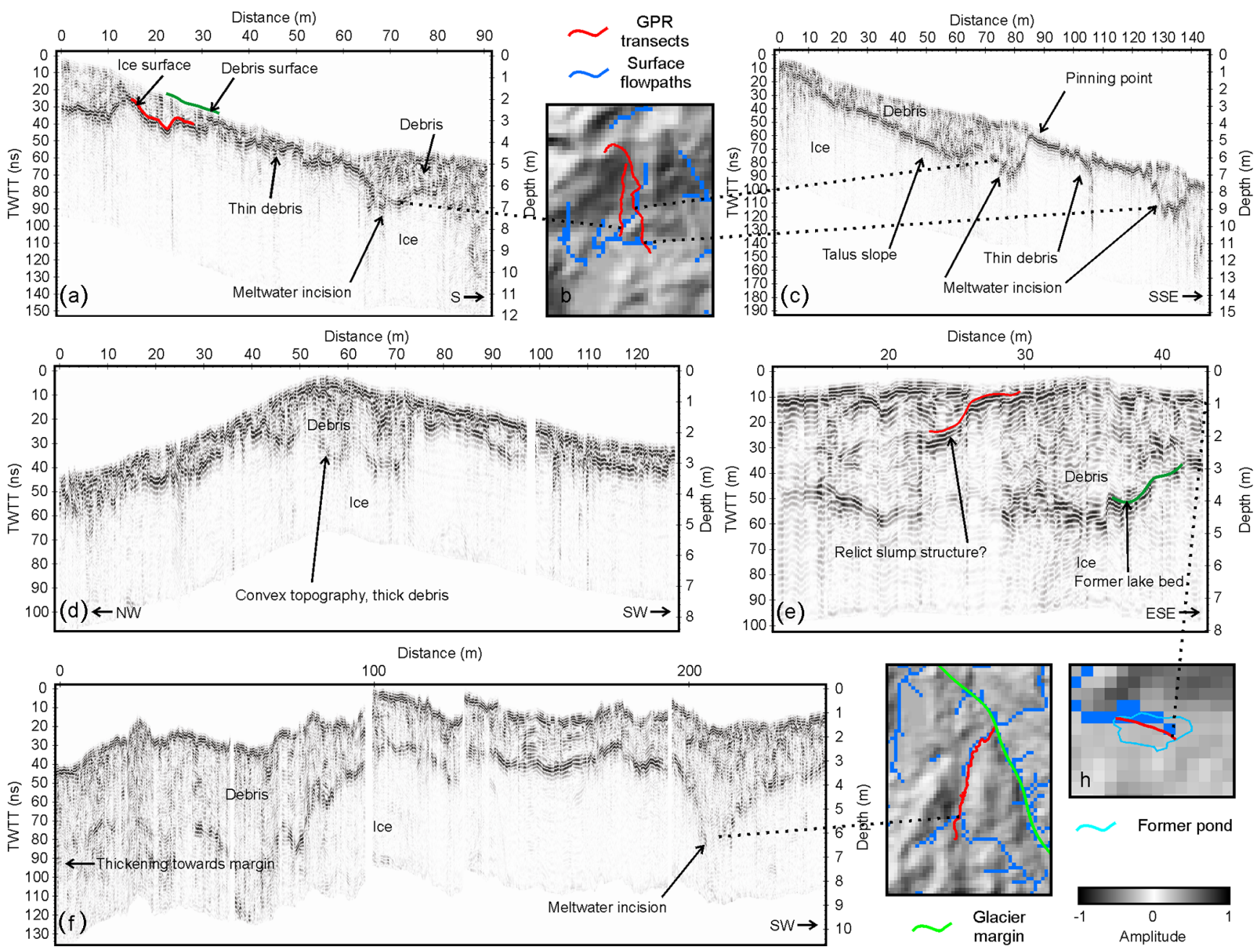

Figure 7. Example of radargrams showing debris thickness variability and internal structures in relation to local topography and surface meltwater flow pathways.

sions are located, indicating that they were likely incised by meltwater. This suggests that meltwater is transported in subdebris supraglacial channels (cf. Miles et al., 2017), but also that meltwater routing has local control over debris thickness by providing topographic lows that become infilled by debris. Additionally, it seems likely that meltwater channels undercut steep slopes, thereby causing debris failure. Steep slopes on debris-covered glaciers are relatively short, so undercutting would have the combined effect of increasing slope angle and also reducing the confining force (or buttressing effect) imparted by downslope debris cover. In some places, thick debris is contained behind pinning points of the underlying ice (Fig. 7a and b), which results in the occurrence of talus slopes (Fig. 7a). This stabilizes the debris and increases the confining force. Thick debris on convex, divergent terrain provides evidence of topographic inversion due to differential ablation (Fig. 7c).

The single glacier margin transect shows increasing debris thickness towards the glacier margin (Figs. $4 \mathrm{~b}$ and $7 \mathrm{e}$ ).
This is expected as a result of (i) material delivered onto the glacier from the inner flanks of the lateral moraines as they are progressively debuttressed by glacier surface lowering, and (ii) lower surface velocities at the glacier margins; hence debris advection rates are slower. The Ngozumpa Glacier and others in the region typically have troughs at the boundary between the glacier and the lateral moraine, and evidence of thicker debris here reinforces the idea that these troughs are eroded by meltwater routed along the glacier margins (Benn et al., 2017).

Since 1984, the development of supraglacial ponds within the Gokyo study area is likely to have affected two areas of radar transects: several transects towards the north of the Gokyo study area, which were partially affected by lakes in 2012 and 2014, and a single transect towards the east of the Gokyo study area, which was partially affected by lakes in all sampled years except 2014 and 2016 (Fig. 4). One of the transects towards the north of the Gokyo study area shows thick debris and some internal structures (Fig. 7e) including 

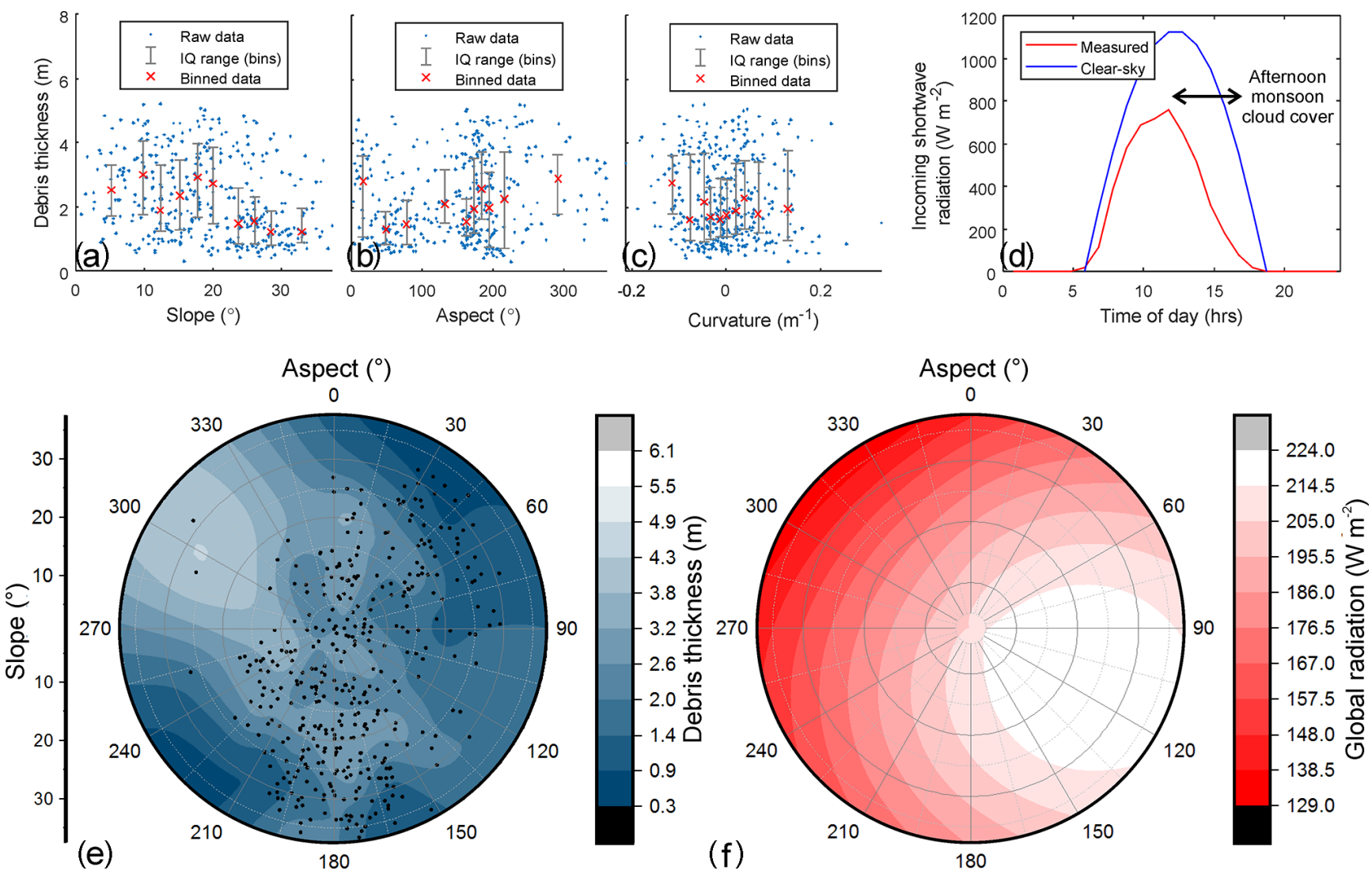

Figure 8. Summary of relationships between measured debris thickness and terrain properties: (a) debris thickness related to local slope angle; (b) debris thickness related to local slope aspect; (c) debris thickness related to curvature; (d) August global radiation data collected on the glacier during the survey period; (e) hemispheric plot of debris thickness (showing subsampled data points) related to slope angle and aspect; (f) hemisphere plot of August global radiation, distributed on surfaces of different slope and aspect following Hock and Noezli (1997).

what may be a relict slump structure, where a package of sediment fell into the lake from its margin as the lake expanded (e.g. Mertes et al., 2016). Thick debris in former supraglacial lakes is likely due to high sedimentation rates in the ponds and slumping at lake margins during lake expansion (Mertes et al., 2016). Modelling suggests that subaqueous sub-debris melt rates are low (Miles et al., 2016), so debris thickening caused by the melt-out of englacial debris is likely to be minimal. The radar stratigraphy over former lake beds suggests multiple near-surface reflectors that can reasonably be interpreted as fine lake sediments overlying coarser supraglacial diamict, suggesting that the locally thicker sediments associated with lakes are due to deposition from sediment-rich supraglacial and englacial meltwaters flowing into a more sluggishly circulating pond.

The debris thickness sampled with GPR in this study does not show distinct relations with slope, aspect or curvature (Fig. 8a, b, c). Binning the thickness data with respect to slope indicates a step decrease in debris thickness above surface slope angles of around $20-23^{\circ}$ (Fig. 8a). This may represent a transition from the low debris transport rates expected on low-gradient, stable slopes to the high debris transport rates expected on steep, failure-prone slopes. While slope and curvature are relatively evenly sampled by the data set, the same is not true for aspect. While southerly and northeasterly aspects are well sampled, samples are scarce in other aspect sectors, rendering interpretation of potential aspect controls on debris thickness difficult (Fig. 8e). Tentatively, our data suggest thin debris is scarcer for north-westerly aspects than others (Fig. 8b, e). Comparing the GPR measurements with both slope and aspect simultaneously (Fig. 8e) shows what would be expected from Fig. 8a, b: that debris tends to be thicker on north-west-facing slopes and thinner on steeper slopes away from the north-westerly sector. During the pre-monsoon in the Himalaya, more melting is likely to occur on south-east-facing slopes than south-west-facing slopes because clouds often reduce incoming shortwave radiation in the afternoon (e.g. Kurosaki and Kimura, 2002; Bhatt and Nakamura, 2005; Shea et al., 2015). This effect is observable in global radiation data (Fig. 8d). Distributing incoming shortwave radiation on slopes of different slopes and aspects reveals the north-western sector to be the one receiving the least solar radiation in midsummer conditions (Fig. 8f). As a result slopes in this sector may be expected 

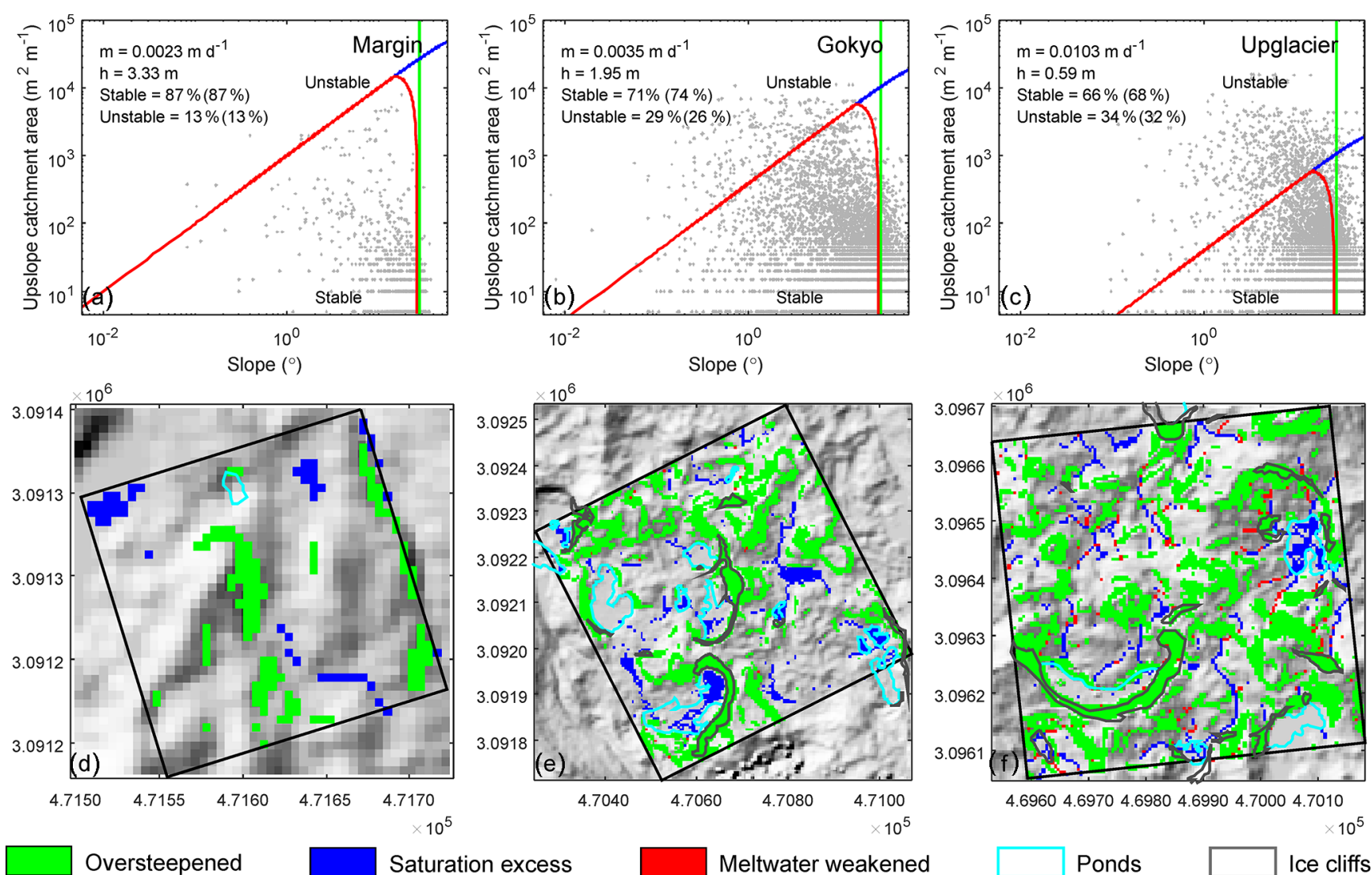

Figure 9. Results of debris stability modelling: upslope catchment area as a function of slope angle for the three study areas (a-c); points falling above or to the right of the plotted lines are unstable. Percentage area of stability and instability values are given with lakes and ice cliffs included and in brackets with lakes and ice cliffs excluded. Maps of spatial distribution of terrain stability classifications for each study area (d-e) highlight ponds and ice cliffs.

to produce less meltwater meaning that debris water content pore pressure remains low, maintaining higher shear strength and greater stability, and allowing thicker debris to be sustained even on steep slopes (Moore, 2017). Samples from steep slopes in the south-eastern sector are scarce, likely due to the higher melt rates resulting from higher solar radiation receipts, serving to reduce slope angles here (Buri and Pellicotti, 2018). As a result of the absence of steep slopes in the south-eastern sector, minimum debris thicknesses are displaced to steeper slope angles flanking the aspect sector or highest midsummer solar radiation receipts. No significant correlations were found between surface curvature and debris thickness (Fig. 8c), but perhaps this is to be expected, as the GPR samples only a snapshot of a dynamically evolving surface. Depending on the stage of topographic inversion sampled, thicker debris could be found at the hummock summit or in the surrounding troughs. Furthermore, the predominance of slope failure over slope creep mechanisms of gravitational reworking would serve to mask any existing relationship with curvature. Ultimately, it seems that the relationship between debris thickness and morphometric terrain parameters (slope, aspect and curvature) is complex.

\subsection{Slope stability modelling}

Slope stability modelling suggests that, under mid-August ablation conditions, the percentage of the debris-covered area interpreted as potentially unstable for the three study areas of Ngozumpa Glacier is between $13 \%$ and $34 \%$, including ponds and ice cliffs and between $13 \%$ and $32 \%$ if ponds and ice cliffs are excluded (Fig. 9). The percentage of potentially unstable surface area increases upglacier, as debris thickness decreases and ablation rates increase (Fig. 6c). Oversteepening was found to be the dominant cause of instability in all three study areas, meaning that the debris is most likely to be unstable where surface slope is greater than $\sim 27^{\circ}$ (i.e. greater than the inverse tangent of the debris-ice interface friction coefficient). In the Gokyo and upglacier study areas, saturation excess was found to be the second most important cause of instability and meltwater weakening the third. Here, it seems that the debris is thin enough and ablation rates high enough for the debris to become saturated with surface meltwater. In the downglacier margin study area, however, meltwater weakening was found to be more important than saturation excess, presumably because the debris here is con- 
siderably thicker and ablation rates providing meltwater are lower.

On the basis that thin debris is more likely to exist on unstable slopes, or on slopes that have recently failed, and that debris-covered glaciers typically extend to lower elevations than debris-free glaciers, these results have important implications for debris-covered glacier surface mass balance. Debris gravitational instability provides a mechanism by which relatively large parts of debris-covered glaciers can experience high melt rates, even if debris is generally thick.

\section{Conclusions}

Debris thickness is known to vary over the surfaces of debriscovered glaciers due to advection, rockfall from valley sides, movement by meltwater and slow cycles of topographic inversion. The debris thickness data presented here suggest that the local debris thickness variability may show characteristic changes in skewness and kurtosis associated with progressive thickening and/or reworking of debris cover over time. On this basis the likely distribution of debris thickness might be predicted by the maturity, or time elapsed since development, of the debris cover found on a glacier surface.

For the thickly debris-covered glaciers of the Himalaya, sub-debris melt rates across the ablation zones are generally considered to be small compared to subaerial melt rates at ice cliffs (e.g. up to $5 \mathrm{~cm} \mathrm{~d}^{-1}$, Watson et al., 2016) and subaqueous bare ice melt rates at supraglacial lakes (e.g. 2$4 \mathrm{~cm} \mathrm{~d}^{-1}$, Miles et al., 2016). Our GPR data confirm that the debris cover on Ngozumpa Glacier is typically thick, with the thickest debris found on shallower slopes or the sites of former supraglacial ponds. Here, the debris is too thick for the daily temperature wave to penetrate to the ice (Nicholson and Benn, 2012). Consequently, even in core ablation season conditions, typical melt rates are low across most of the debriscovered area. However, processes of debris destabilization can form areas of thin debris within thicker debris. These areas of thinner debris skew the spatially averaged ablation rate in a manner that is analogous to that caused by exposed ice faces. Here, sub-debris melt rates under thinner debris are expected to be significantly above average and even comparable with bare ice melt rates further upglacier. We find that using mean debris thickness values in surface mass balance models is likely to cause melt to be underestimated, and our results confirm previous suggestions that debris thickness is better represented in surface mass balance models as a probability density function (e.g. Nicholson and Benn, 2012; Reid et al., 2012).

On the surface of the Ngozumpa Glacier, our data suggest that topography is important for additional local control on debris thickness distribution via slope and hydrological processes and also that thick sediment deposits at the beds of former supraglacial ponds are an important additional control on the local variability of debris thickness. Surface debris appears to be mobilized and transported by slope- and aspectdependent sliding caused by sub-debris melting and most likely triggered by meltwater activity. Debris is redistributed from steep slopes to shallow slopes and to ice-surface depressions that are often of hydrological origin. However, the relationship between debris thickness and morphometric terrain parameters is complex. While there is some apparent variation of debris thickness with slope and aspect, whereby thinner debris caused by slope failure is more likely to occur on steeper slopes with aspects that receive more abundant solar radiation, we find no meaningful variation with curvature. This, combined with observations of slide-type debris morphology, suggests that mass movement on the Ngozumpa Glacier occurs on relatively short timescales and predominantly by processes that occur at the limits of gravitational stability (e.g. Moore, 2017). Slope stability modelling suggests that large areas of the glacier are potentially prone to failure, and thus, as failure forms areas of thinner debris, that melting in these areas might be important on the glacier scale.

Data availability. Debris thickness data measured on Ngozumpa Glacier are publicly available at https://zenodo.org/ (23 November 2018) with DOI: https://doi.org/10.5281/zenodo.1451560 (Nicholson and McCarthy, 2018).

Author contributions. LN, MM and HP contributed to field data collection. LN analysed the debris thickness distributions, performed melt modelling and led the preparation of the manuscript. MM, with guidance from HP and IW, processed the GPR data and performed terrain analysis and slope stability modelling. All authors contributed to finalizing the manuscript.

Competing interests. The authors declare that they have no conflict of interest.

Acknowledgements. This research is supported by the Austrian Science Fund (FWF) projects V309 and P28521 and the Austrian Space Applications Program of the Austrian Research promotion agency (FFG) project 847999. Michael McCarthy is funded by NERC DTP grant number NE/L002507/1 and receives CASE funding from Reynolds International Ltd. Hamish Pritchard was funded by a British Antarctic Survey collaboration grant. The field team in Nepal was Ursula Blumthaler, Mohan Chand, Costanza del Gobbo, Alexander Groos, Astrid Lambrecht, Christoph Mayer, Hamish Pritchard, Lorenzo Rieg, Anna Wirbel. Christoph Klug generated the DEM. Debris thicknesses data on Haut Glacier d'Arolla were collected by Marco Carenzo, Francesca Pelliciotti and Lene Peterson and provided by Tim Reid.

Edited by: Valentina Radic

Reviewed by: Peter Moore and one anonymous referee 


\section{References}

Arthern, R. J., Winebrenner, D. P., and Vaughan, D. G.: Antarctic snow accumulation mapped using polarization of $4.3 \mathrm{~cm}$ wavelength microwave emission, J. Geophys. Res.-Atmos., 111, 1-10, https://doi.org/10.1029/2004JD005667, 2006.

Barrette, P. D. and Timco, G. W.: Laboratory study on the sliding resistance of level ice and rubble on sand, Cold Reg. Sci. Technol., 54, 73-82, https://doi.org/10.1016/j.coldregions.2008.02.002, 2008.

Benn, D. I., Wiseman, S., and Warren, C. R.: Rapid growth of a supraglacial lake, Ngozumpa Glacier, Khumbu Himal, Nepal, IAHS-AISH P., 264, 177-185, 2000.

Benn, D. I., Wiseman, S., and Hands, K. A.: Growth and drainage of supraglacial lakes on debrismantled Ngozumpa Glacier, Khumbu Himal, Nepal, J. Glaciol., 47, 626-638, https://doi.org/10.3189/172756501781831729, 2001.

Benn, D. I., Kirkbride, M., Owen, L. A., and Brazier, V.: Glaciated Valley Landsystems, in: Glacial Landsystems, edited by: Evans, D. J. A., Arnold, London, 2003.

Benn, D. I., Thompson, S., Gulley, J., Mertes, J., Luckman, A., and Nicholson, L.: Structure and evolution of the drainage system of a Himalayan debris-covered glacier, and its relationship with patterns of mass loss, The Cryosphere, 11, 2247-2264, https://doi.org/10.5194/tc-11-2247-2017, 2017.

Bhatt, B. C. and Nakamura, K.: Characteristics of Monsoon Rainfall around the Himalayas Revealed by TRMM Precipitation Radar, Mon. Weather Rev., 133, 149-165, https://doi.org/10.1175/MWR-2846.1, 2005.

Bolch, T., Buchroithner, M., Pieczonka, T., and Kunert, A.: Planimetric and volumetric glacier changes in the Khumbu Himal, Nepal, since 1962 using Corona, Landsat TM and ASTER data, J. Glaciol., 54, 592-600, https://doi.org/10.3189/002214308786570782, 2008.

Buri, P. and Pellicciotti, F.: Aspect controls the survival of ice cliffs on debris-covered glaciers, P. Natl. Acad. Sci. USA, 115, 201713892, https://doi.org/10.1073/pnas.1713892115, 2018.

Buri, P., Pellicciotti, F., Steiner, J. F., Miles, E. S., and Immerzeel, W. W.: A grid-based model of backwasting of supraglacial ice cliffs on debris-covered glaciers, Ann. Glaciol., 57, 199-211, https://doi.org/10.3189/2016AoG71A059, 2016.

Conway, H. and Rasmussen, L. A.: Summer temperature profiles within supraglacial debris on Khumbu Glacier, Nepal, IAHSAISH P., 264, 89-97, 2000.

del Gobbo, C.: Debris thickness investigation of Solda glacier, southern Rhaetian Alps, Italy: Methodological considerations about the use of ground penetrating radar over a debris-covered glacier, MSc Thesis, University of Innsbruck, 2017.

Evatt, G. W., Abrahams, I. D., Heil, M., Mayer, C., Kingslake, J., Mitchell, S. L., Fowler, A. C., and Clark, C. D.: Glacial melt under a porous debris layer, J. Glaciol., 61, 825-836, https://doi.org/10.3189/2015JoG14J235, 2015.

Fetter, C.: Applied Hydrogeology, Macmillan, 1994.

Fawcett, T.: An introduction to ROC analysis, Pattern Recognit. Lett., 27, 861-874, https://doi.org/10.1016/j.patrec.2005.10.010, 2006.

Finsterwalder, S. and lagally, M.: Die Nuevermessung des Suldenferers 1906 und dessen Veränderungen in den letzten Jahrzehnten, Zeitschrift für Gletscherkunde, 13, 1-7, 1913.
Foster, L. A., Brock, B. W., Cutler, M. E. J., and Diotri, F.: A physically based method for estimating supraglacial debris thickness from thermal band remote-sensing data, J. Glaciol., 58, 677-691, https://doi.org/10.3189/2012JoG11J194, 2012.

Gibson, M. J., Glasser, N. F., Quincey, D. J., Mayer, C., Rowan, A. V., and Irvine-Fynn, T. D. L.: Temporal variations in supraglacial debris distribution on Baltoro Glacier, Karakoram between 2001 and 2012, Geomorphology, 295, 572-585, https://doi.org/10.1016/j.geomorph.2017.08.012, 2017.

Heimsath, A. M., Dietrichs, W. E., Nishiizuml, K., and Finkel, R. C.: The soil production function and landscape equilibrium, Nature, 388, 358-361, https://doi.org/10.1038/41056, 1997.

Heimsath, A. M., DiBiase, R. A., and Whipple, K. X.: Soil production limits and the transition to bedrock-dominated landscapes, Nat. Geosci., 5, 210-214, doi:10.1038/ngeo1380, 2012.

Herreid, S. and Pellicciotti, F.: Automated detection of ice cliffs within supraglacial debris cover, The Cryosphere, 12, 18111829, https://doi.org/10.5194/tc-12-1811-2018, 2018.

Hirschmüller, H.: Stereo processing by semiglobal matching and mutual information, IEEE Transaction on Pattern Analysis and Machine Intelligence, 30, 328-341, 2008.

Hock, R. and Noetzli, C.: Area melt and discharge modelling of Storglaciären, Sweden, Ann. Glaciol., 24, 211-216, https://doi.org/10.1017/S0260305500012192, 1997.

Juen, M., Mayer, C., Lambrecht, A., Han, H., and Liu, S.: Impact of varying debris cover thickness on ablation: a case study for Koxkar Glacier in the Tien Shan, The Cryosphere, 8, 377-386, https://doi.org/10.5194/tc-8-377-2014, 2014.

Kayastha, R. B., Takeuchi, Y., Nakawo, M., and Ageta, Y.: Practical prediction of ice melting beneath various thickness of debris cover on Khumbu Glacier, Nepal, using a positive degree-day factor, IAHS-AISH P., 264, 71-81, 2000.

Kääb, A., Berthier, E., Nuth, C., Gardelle, J., Arnaud, Y., Kaab, A., Berthier, E., Nuth, C., Gardelle, J., and Arnaud, Y.: Contrasting patterns of early twenty-first-century glacier mass change in the Himalayas, Nature, 488, 495-498, https://doi.org/10.1038/nature11324, 2012.

Kirkbride, M. P.: Ice-marginal geomorphology and Holocene expansion of debris-covered Tasman Glacier, New Zealand, IAHSAISH P., 264, 211-217, 2000.

Kraaijenbrink, P. D. A., Bierkens, M. F. P., Lutz, A. F., and Immerzeel, W. W.: Impact of a global temperature rise of 1.5 degrees Celsius on Asia's glaciers, Nature, 549, 257-260, https://doi.org/10.1038/nature23878, 2017.

Kurosaki, Y. and Kimura, F.: Relationship between Topography and Daytime Cloud Activity around Tibetan Plateau., J. Meteorol. Soc. Japan, 80, 1339-1355, https://doi.org/10.2151/jmsj.80.1339, 2002.

Lawson, D.: Semdimentological Analysis of the Western Terminus Region of the Matanuska Glacier, Alaska, Cold Regions Research and Engineering Lab: Hanover, NH, 1979.

Loomis, S. R.: Morphology and ablation processes on glacier ice, Proceedings of the Association of American Geographers, 12, 88-92, 1970.

Mattson, L. E., Gardner, J. S. and Young, G. J.: Ablation on debris covered glaciers: an example from the Rakhiot Glacier, Punjab, Himalaya, in: IAHS-AISH P., edited by: Young, G. J., Wallingford, 218, 289-296, 1993. 
McCarthy, M., Pritchard, H. D., Willis, I., and King, E.: Ground-penetrating radar measurements of debris thickness on Lirung Glacier, Nepal, J. Glaciol., 63, 534-555, https://doi.org/10.1017/jog.2017.18, 2017.

Mertes, J. R., Thompson, S. S., Booth, A. D., Gulley, J. D., and Benn, D. I.: A conceptual model of supra-glacial lake formation on debris-covered glaciers based on GPR facies analysis, Earth Surf. Process. Landforms, 42, 903-914, https://doi.org/10.1002/esp.4068, 2016.

Mertes, J. R., Thompson, S. S., Booth, A. D., Gulley, J. D., and Benn, D. I.: A conceptual model of supraglacial lake formation on debris-covered glaciers based on GPR facies analysis, Earth Surf. Proc. Land., 42, 903-914, https://doi.org/10.1002/esp.4068, 2017.

Mihalcea, C., Mayer, C., Diolaiuti, G., Lambrecht, A., Smiraglia, C., and Tartari, G.: Ice ablation and meteorological conditions on the debris-covered area of Baltoro glacier, Karakoram, Pakistan, Ann. Glaciol., 43, 292-300, 2006.

Mihalcea, C., Brock, B. W., Diolaiuti, G., D’Agata, C., Citterio, M., Kirkbride, M. P., Cutler, M. E. J., and Smiraglia, C.: Using ASTER satellite and ground-based surface temperature measurements to derive supraglacial debris cover and thickness patterns on Miage Glacier (Mont Blanc Massif, Italy), Cold Reg. Sci. Technol., 52, 341-354, 2008a.

Mihalcea, C., Mayer, C., and Diolaiuti, G.: Spatial distribution of debris thickness and melting from remote-sensing and meteorological data, at debris-covered Baltoro glacier, Karakoram, Pakistan, Ann. Glaciol., 48, 49-57, 2008 b.

Miles, E. S., Pellicciotti, F., Willis, I. C., Steiner, J. F., Buri, P., and Arnold, N. S.: Refined energy-balance modelling of a supraglacial pond, Langtang Khola, Nepal, Ann. Glaciol., 57, 29-40, https://doi.org/10.3189/2016AoG71A421, 2016.

Miles, K. E., Hubbard, B., Irvine-Fynn, T. D. L., Miles, E. S., Quincey, D. J., and Rowan, A. V.: Review article: The hydrology of debris-covered glaciers - state of the science and future research directions, The Cryosphere Discuss., https://doi.org/10.5194/tc-2017-210, 2017.

Moore, P. L.: Stability of supraglacial debris, Earth Surf. Process. Landforms, 43, 285-297, https://doi.org/10.1002/esp.4244, 2018.

Nicholson, L. I. and Benn, D. I.: Calculating ice melt beneath a debris layer using meteorological data, J. Glaciol., 52, 463-470, 2006.

Nicholson, L. I. and Benn, D. I.: Properties of natural supraglacial debris in relation to modelling sub-debris ice ablation, Earth Surf. Proc. Land., 38, 409-501, https://doi.org/10.1002/esp.3299, 2012.

Nicholson, L. and McCarthy, M.: Supraglacial debris thickness data from Ngozumpa Glacier, Nepal, https://doi.org/10.5281/zenodo.1451560, 2018.

Nicholson, L. and Mertes, J.: Thickness estimation of supraglacial debris above ice cliff exposures using a high-resolution digital surface model derived from terrestrial photography, J. Glaciol., 63, 989-998, https://doi.org/10.1017/jog.2017.68, 2017.

Nuimura, T., Fujita, K., Yamaguchi, S., and Sharma, R. R.: Elevation changes of glaciers revealed by multitemporal digital elevation models calibrated by GPS survey in the Khumbu region, Nepal Himalaya, 1992-2008, J. Glaciol., 58, 648-656, https://doi.org/10.3189/2012JoG11J061, 2012.
Østrem, G.: Ice melting under a thin layer of moraine, and the existence of ice cores in moraine ridges, Geografiska Ann., 51, 228230, 1959.

Pelletier, J. D. and Rasmussen, C.: Geomorphically based predictive mapping of soil thickness in upland watersheds, Water Resour. Res., 45, 1-15, https://doi.org/10.1029/2008WR007319, 2009.

Quincey, D. J., Luckman, A., and Benn, D. I.: Quantification of Everest region glacier velocities between 1992 and 2002, using satellite radar interferometry and feature tracking, J. Glaciol., 55, 596-606, https://doi.org/10.3189/002214309789470987, 2009.

Reid, T. D. and Brock, B. W.: An energy-balance model for debriscovered glaciers including heat conduction through the debris layer, J. Glaciol., 56, 903-916, 2010.

Reid, T. D., Carenzo, M., Pellicciotti, F., and Brock, B. W.: Including debris cover effects in a distributed model of glacier ablation, J. Geophys. Res., 117, 1-15, https://doi.org/10.1029/2012JD017795, 2012.

Rieg, L., Klug, C., Nicholson, L., and Sailer, R.: Pléiades TriStereo Data for Glacier Investigations - Examples from the European Alps and the Khumbu Himal, Remote Sens., 10, 1563, https://doi.org/10.3390/rs10101563, 2018.

Rounce, D. R. and McKinney, D. C.: Debris thickness of glaciers in the Everest area (Nepal Himalaya) derived from satellite imagery using a nonlinear energy balance model, The Cryosphere, 8, 1317-1329, https://doi.org/10.5194/tc-8-1317-2014, 2014

Rowan, A. V.: The "Little Ice Age" in the Himalaya: A review of glacier advance driven by Northern Hemisphere temperature change, Holocene, 27, 292-308, https://doi.org/10.1177/0959683616658530, 2017.

Sakai, A., Takeuchi, N., Fujita, K., and Nakawo, M.: Role of supraglacial ponds in the ablation process of a debris-covered glacier in the Nepal Himalayas, IAHS-AISH P., 265, 119-132, 2000.

Schauwecker, S., Rohrer, M., Huggel, C., Kulkarni, A., Ramanathan, A. L., Salzmann, N., Stoffel, M., and Brock, B. W.: Remotely sensed debris thickness mapping of Bara Shigri Glacier, Indian Himalaya, J. Glaciol., 61, 675-688, https://doi.org/10.3189/2015JoG14J102, 2015.

Shea, J. M., Wagnon, P., Immerzeel, W. W., Biron, R., Brun, F., and Pellicciotti, F.: A comparative high-altitude meteorological analysis from three catchments in the Nepalese Himalaya, Int. J. Water Resour. Dev., 31, 1-27, https://doi.org/10.1080/07900627.2015.1020417, 2015.

Thompson, S. S., Benn, D. I., Dennis, K., and Luckman, A.: A rapidly growing moraine-dammed glacial lake on Ngozumpa Glacier, Nepal, Geomorphology, 145-146, 1-11, https://doi.org/10.1016/j.geomorph.2011.08.015, 2012.

Thompson, S. S., Benn, D. I., Mertes, J., and Luckman, A.: Stagnation and mass loss on a Himalayan debris-covered glacier: Processes, patterns and rates, J. Glaciol., 62, 467-485, https://doi.org/10.1017/jog.2016.37, 2016.

Wagnon, P., Vincent, C., Arnaud, Y., Berthier, E., Vuillermoz, E., Gruber, S., Ménégoz, M., Gilbert, A., Dumont, M., Shea, J. M., Stumm, D., and Pokhrel, B. K.: Seasonal and annual mass balances of Mera and Pokalde glaciers (Nepal Himalaya) since 2007, The Cryosphere, 7, 1769-1786, https://doi.org/10.5194/tc7-1769-2013, 2013. 
Watson, C. S., Quincey, D. J., Carrivick, J. L., and Smith, M. W.: The dynamics of supraglacial ponds in the Everest region, central Himalaya, Glob. Planet. Change, 142, 14-27, , 2016.

Zhang, Y., Fujita, K., Liu, S., Liu, Q., and Nuimura, T.: Distribution of debris thickness and its effect on ice melt at Hailuogou glacier, southeastern Tibetan Plateau, using in situ surveys and ASTER imagery, J. Glaciol., 57, 1147-1157, https://doi.org/10.3189/002214311798843331, 2011. 